\title{
Axial Ferrite-Magnet-Assisted Synchronous Reluctance Motor
}

\author{
P. Akiki, M. Hage-Hassan, M. Bensetti, J-C. Vannier, D. Prieto and Mike McClelland
}

\begin{abstract}
This paper presents a noval 18 poles /16 slots Axial Flux Permanent Magnet-Assisted Synchronous Reluctance Motor (AF-PMASynRM) with non-overlapping concentrated winding. At first, the torque ripple and iron losses are analyzed using 3D Finite Element Analysis (3D-FEA). Then, a comparison between 3D-FEA and 2D-FEA based on flux and iron losses is established. In this paper, we propose to design the motor for high torque low speed application using a multiobjective optimization. In this kind of iterative procedure, the use of Finite Element is generally time consuming. Thus, we propose a $2 \mathrm{D}$ analytical saturated model that considers the local saturation near the iron bridges and the slot tangential leakage flux. The magnetic model is coupled with an electrical model that computes the power factor and the voltage at the motor terminals. A loss model is also developed to calculate the copper and the iron losses. The proposed analytical model is $\mathbf{5}$ times faster than the 2D-FEA. The optimal axial structure is compared to a previously optimized radial motor in order to evaluate the design benefits of axial flux machines.
\end{abstract}

Index Terms-Analytical model, Concentrated winding, Electrical machines, IPM motor, Multi-V-shape magnets.

\section{INTRODUCTION}

$\mathrm{R}$ ECENTLY, high performance motors for direct drive applications have been the subject of many studies and research projects. Permanent magnet motors with rare-earth magnets are very good candidates and have been widely used by industrials during the last decades [1]. However, the unstable price of rare earth magnets led the manufacturers to study new topologies that avoid using these materials [2]. Non-rare-earth permanent magnets such as ferrite have attracted significant interest. However, the low magnetic field created by these types of magnet leads to their use as an additional torque source in synchronous reluctance motors. This configuration is known as the Permanent Magnet Assisted Synchronous Reluctance Motor [3] - [5]. In previous work [6], we proposed to study an 18 slots and 16 poles radial flux motor with two V-shape barriers per pole filled with ferrite magnets with non-overlapping concentrated winding. A developed multiphysics model considering the electromagnetic, thermal and mechanical coupling was proposed and experimentally validated.

The literature on the design of Axial Flux Permanent Magnet Machine (AFPM), includes, for example, the study of toothless structures that reduces the core losses [7], the influence

P. Akiki, M. Hage Hassan, J-C. Vannier and Mohamed Bensetti are with GeePs - Group of electrical engineering-Paris, UMR CNRS 8507, CentraleSuplec, Univ.Paris-Sud, Sorbonne Universits,3, rue Joliot-Curie, Plateau de Moulon 91192 Gif-sur-Yvette, France. (emails :paul.akiki@centralesupelec.fr, maya.hagehassan@centralesupelec.fr.

Dany Prieto and Mike McClelland are with Leroy Somer Motor, 16000 Angoulłme, France. (e-mail: mike.mcclelland@mail.nidec.com). of rotor thickness on efficiency [8] and the optimization of PMs shape in order to reduce the cogging torque [9]. In most of these studies, axial flux machines are presented with surface rare-earth PM. Besides, recent work addressed AFPMASynRM [10], [11]. In this paper, a Ferrite Magnet Assisted Synchronous Reluctance Motor with U-shape barriers is proposed. The studied structure is a double rotor single stator configuration with short end-winding that reduces the Joule losses.

Firstly, the effect of the iron ribs on the torque ripple is studied and the used materials are investigated to decrease the iron losses. Thus, a comparative study is proposed using ferromagnetic sheets and soft magnetic composite (SMC). These studies are carried out by means of 3D-FEA using $\mathrm{JMAG}^{\circledR}$. In addition, a comparison between the 3D-FEA and a linearized 2D-FEA models of the machine is conducted in order to validate the $2 \mathrm{D}$ approach for the axial flux structure. Secondly, an electromagnetic analytical model of the 2D linearized AFM is detailed. It is based on an earlier developed model for the radial flux machine [6]. The model takes into consideration the saturation in the rotor and the stator parts, the leakage flux in the slots and the local saturation in the areas next to the iron ribs. The developed model is parameterized as a function of the slot number, the pole pair number and the magnet layer number. An electrical model is developed to determine the power factor and the voltage at the motor terminals. A loss model is also proposed to determine the copper and the iron losses in the stator and the rotor parts. The work presented in this paper aims to propose the most cost-effective solution for a given low speed and high torque application. Thus, a comparison between the radial and axial flux machines is conducted. The comparison based on subjective geometrical constraints may sometimes favor one configuration over the other. Therefore, in this paper, a mutliobjective optimization based on NSGA-II algorithm [12] is used to optimize both machines in order to meet the same specifications. The presented comparison procedure is based on the optimal design of the radial and axial flux structures operating at the same steady-state temperature.

\section{ANALYSIS OF AXIAL FLUX MACHINE}

The studied structure (Fig. 1) is of Torus type [13], with a single stator to reduce the copper losses. The machine is a three-phase motor and is designed with a non-overlapping concentrated tooth winding. A double layer winding is chosen so that the fundamental winding factor for the 18 slots/16 poles design is high and equal to 0.945 which makes this topology suitable for high torque production. Due to magnetic and geometrical symmetries, only quarter of the machine needs to be modeled. The AFM is of NS (North-South) type; 


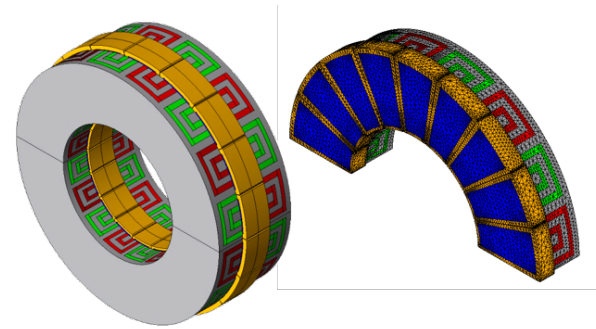

Fig. 1. Axial flux 18/16 machine double rotor/single stator with concentrated winding

thus, such structure does not require, in principle, any stator yoke. The main flux crosses the stator axially and is reversed within the rotor yokes. Hence, the overall axial length is rather short and the iron losses can be reduced in the stator part. The high torque ripple is a common problem in synchronous reluctance machines [14]. Even though the 18poles/16 slots structure exhibits a smooth torque, the iron ribs may have influence on torque ripple [15]. Thus, the effect of iron ribs in case of synchronous reluctance axial flux machine assisted by PM is investigated. The main characteristics of the machine $M_{1}$ are given in Table. I.

TABLE I

MAIN GEOMETRICAL DIMENSIONS

\begin{tabular}{c|c} 
& $M_{1}$ \\
\hline Exterior radius $: R_{\text {ext }}$ & $140 \mathrm{~mm}$ \\
\hline Interior radius $: R_{\text {int }}$ & $80 \mathrm{~mm}$ \\
\hline Rotor height: $h_{\text {rotor }}$ & $55 \mathrm{~mm}$ \\
\hline Rated speed: $N$ & $500 \mathrm{rpm}$ \\
\hline Number of turns per coil & 40 \\
\hline Ferrite magnet remanence & $0.4 \mathrm{~T}$ \\
\hline Airgap & $1 \mathrm{~mm}$
\end{tabular}

\section{A. Analysis of Torque ripple}

Two axial flux structures with and without iron ribs are presented in Fig. 2. When considering the irons ribs, their thickness is fixed to $0.7 \mathrm{~mm}$, The machines are simulated using FEA over $360^{\circ}$ electrical degrees, at $40 \mathrm{~A}$ (rms). The electromagnetic torque is computed by means of the Maxwell stress tensor along the airgap. The torque ripple amplitude is given by:

$$
\Delta T=\frac{T_{\max }-T_{\min }}{T_{a v g}}
$$

Due to the presence of iron ribs (iron bridges), the average torque is reduced compared to the structure without these iron bridges (218 Nm and $225.16 \mathrm{Nm}$ respectively). In fact, PMs are used to saturate the outer bridges which affects the airgap flux density and the torque. Besides, the configuration without iron ribs exhibits high harmonics amplitude (Fig. 3). The absence of iron ribs has a significant effect on torque ripple, $\Delta T$ varies from $8.2 \%$ to $14.9 \%$.

Based on the previous study, the iron ribs are maintained. In the next paragraph, the influence of the stator magnetic material on iron losses is analyzed.

\section{B. Magnetic material analysis: steel sheets and SMC}

The iron losses of two types of stator magnetic material are compared. One is with laminated M400P-50, which can be made with long sheets of steel rolled up. The other is made of

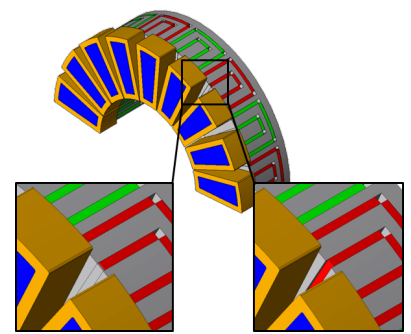

Fig. 2. Axial flux machine: with iron ribs (left), without iron ribs (right)
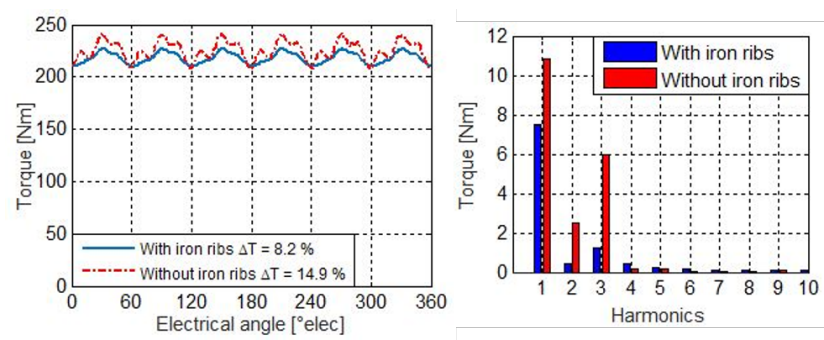

Fig. 3. Torque ripple and harmonics amplitude at $40 \mathrm{~A}$ (rms)

soft magnetic composite (SMC) Somaloy 700-3P. The SMC is made from powder iron material that can be theoretically molded into any shape using a process similar to the plastic injection molding. For the rotor, due to its complex shape, the chosen material is the SMC. The results are given in Table. II. It is interesting to observe that the higher iron losses $\left(P_{i l}\right)$ are obtained when the stator teeth are made with SMC. In fact, the SMC reduces the eddy current losses $\left(P_{E C}\right)$ but increases the hysteresis losses $\left(P_{\text {hyst }}\right)$ at low frequencies. Therefore, for low speed applications (500 rpm in our case), the use of SMC causes the augmentation of total iron losses. Thus, the steel sheet will be used for the stator.

TABLE II

3D IRON LOSSES COMPARISON

\begin{tabular}{c|c|c|c} 
& \multicolumn{3}{|c}{ Iron losses 3D $(\mathbf{W})$} \\
\hline & P hyst & $\mathbf{P}_{\mathbf{E C}}$ & $\mathbf{P}_{\text {il }}$ \\
\hline Stator M400P-50 & 25.53 & 21 & $\mathbf{4 6 . 5 3}$ \\
\hline Rotor SMC & 107.11 & 7.23 & $\mathbf{1 1 4 . 3 5}$ \\
\hline \hline Stator SMC & 96.81 & 2.38 & $\mathbf{9 9 . 1 9}$ \\
\hline Rotor SMC & 101.38 & 6.99 & $\mathbf{1 0 8 . 3 8}$ \\
\hline
\end{tabular}

\section{MAGNETIC MODEL}

In order to meet the required specifications, a multiobjective optimization of the axial flux (AF) machine is proposed. In an iterative procedure, the use of a 3D-FEA model is a heavy and time consuming operation. Thus, it is convenient to use a faster model.

In the next paragraphs, a linearized 2D finite element model of the studied motor is created and its results are compared with those of 3D-FE. Then, a 2D saturated analytical modeling of the axial flux machine is proposed in order to compute the flux density in the different parts of the motor. The modeling method was presented in [6] and validated experimentally. It relies on Maxwell equations. The analytical model is used to determine the motors performances such as the power factor, the mean torque, and the efficiency.

\section{A. Linearized 2D magnetic model}

The $2 \mathrm{D}$ equivalent linear machine is proposed in Fig. 4. The mean radius $\left(R_{\text {mean }}\right)$ given in $(2)$ is used to calculate 
the active equivalent length $\left(l_{e q}\right)$ and depth $\left(\right.$ dept $\left._{e q}\right)(3)$ that maintain the same active surface between the $3 \mathrm{D}$ and the $2 \mathrm{D}$ models (red surfaces in Fig. 5).

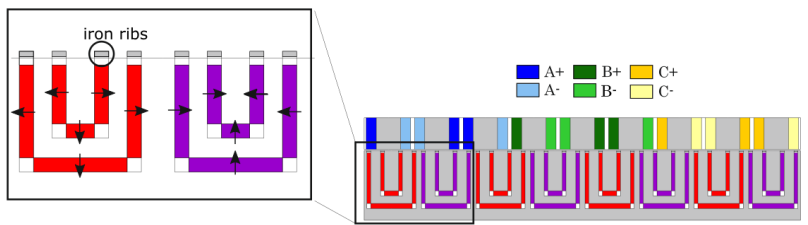

Fig. 4. 2D equivalent axial flux machine- quarter of the motor is presented

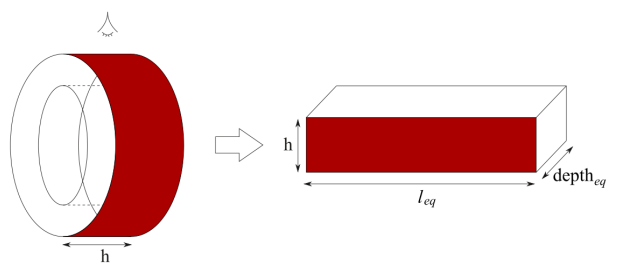

Fig. 5. 2D equivalent active surface

$$
\begin{gathered}
R_{e q}=R_{\text {mean }}=\left(R_{\text {ext }}+R_{\text {int }}\right) / 2 \\
\text { depth } h_{e q}=R_{\text {ext }}-R_{\text {int }} \quad ; \quad l_{e q}=2 \pi R_{e q}
\end{gathered}
$$

\section{B. Comparison of the $3 D$ and $2 D$ FE models}

To validate the $2 \mathrm{D}$ linearization of the AFM, a comparison with the $3 \mathrm{D}$ model is conducted using $\mathrm{JMAG}^{\circledR}$ software. The phase A flux linkage at $40 \mathrm{~A}$ is given in Fig. 6. It shows a good concordance between the 2D FEA and 3D FEA, with an error of $1.66 \%$. The use of a multilayer linearized model is also investigated, the error when using 1,5 , or 10 layers is inferior to $1 \%$ (Fig. 6), and thus a single layer with $\left(R_{\text {mean }}\right)$ linearized model is adopted. The performances of the machine will be used in an optimization procedure, thus the error on losses between 2D and 3D FEA should be also evaluated. The results of the comparison on motor $M_{1}$ are given in Table. III. The error is less than $2 \%$. The necessary time to evaluate 60 points is $12 \mathrm{~min}$ in $2 \mathrm{D}$ FEA, and is up to $8 \mathrm{~h} 30 \mathrm{~min}$ in $3 \mathrm{D}$ FEA. The FE were computed using Intel ${ }^{\circledR}$ Core i7-4600U CPU @2.10GHz 2.70GHz with 16GB RAM. The 3D-FEA has about 46300 nodes and 190000 elements, and the 2DFEA has about 4500 nodes and 8000 elements. Therefore, the $2 \mathrm{D}$ model is retained and an analytical model based on Maxwell's equations is proposed.

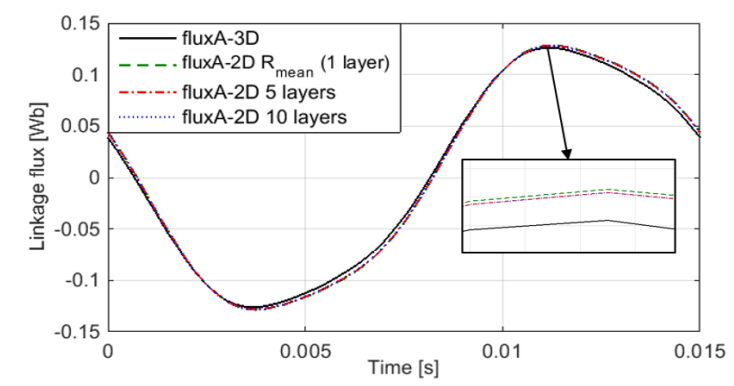

Fig. 6. Flux linkage of phase A is compared between 3D-FEA and 2D-FEA with different number of layers
TABLE III

2D/3D IRON LOSSES COMPARISON

\begin{tabular}{c|c|c|c|c} 
& \multicolumn{3}{|c}{$\mathbf{P}_{\mathbf{i l}} \mathbf{2 D}(\mathbf{W})$} & error to 3D \\
\hline & $\mathbf{P}_{\text {hyst }}$ & $\mathbf{P}_{\mathbf{E C}}$ & $\mathbf{P}_{\mathbf{i l}}$ & \\
\hline Stator M400P-50 & 25.29 & 21.74 & $\mathbf{4 7 . 0 3}$ & $\mathbf{1 \%}$ \\
\hline Rotor SMC & 109.31 & 5.9 & $\mathbf{1 1 5 . 2 1}$ & $\mathbf{0 . 7} \%$ \\
\hline \hline Stator SMC & 97.06 & 2.59 & $\mathbf{9 9 . 6 5}$ & $\mathbf{0 . 4} \%$ \\
\hline Rotor SMC & 104.36 & 5.62 & $\mathbf{1 0 9 . 9 8}$ & $\mathbf{1 . 4} \%$ \\
\hline
\end{tabular}

\section{Analytical global system}

The magnetomotive force $(m m f)$ is determined with respect to the winding pattern given in Fig.5. The $m m f$ level of each tooth is given by the total current of the tooth coil. A linear variation of the $m m f$ is considered in the slots [6]. The general scheme of the model that links the stator and the rotor, is given in Fig. 7. A non-linear system is established by applying Ampere's theorem on the contours $C_{1}$ to $C_{4}$ and the flux conservation law on the stator and rotor parts. The system is formed of $n$ equations with $n$ variables given in the unknown vector $X$ (4). The non-linear equations of the magnetic model are solved using Broyden's method.

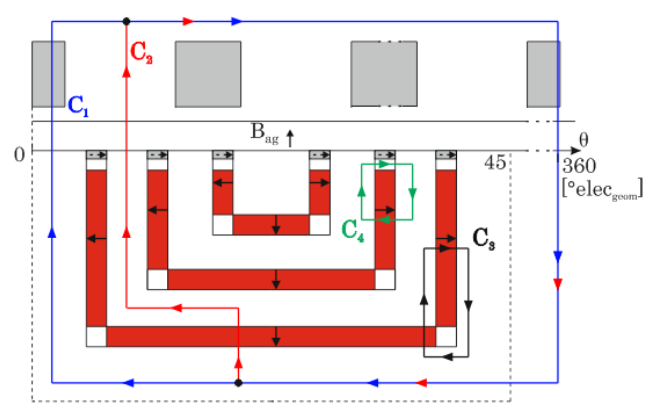

Fig. 7. Motor general schematic and flux paths

$$
\underbrace{X}_{n \text { variables }}=[\underbrace{\left[B_{a g}\right]}_{q \text { variables }} \underbrace{\left[B_{p m_{\text {rad }}}\right]}_{r \text { variables }} \underbrace{\left[B_{\text {air }}\right]}_{\text {variables }} \underbrace{\left[B_{i b}\right]}_{t \text { variables }}]
$$

$B_{a g}$ is the airgap flux density, $B_{p m_{\text {rad }}}$ is the radial permanent magnet flux density, $B_{i b}$ is the tangential iron rib flux density, and $B_{a i r}$ is the flux density in the air spaces between the magnets and the iron bridges. Before considering the equations on the different contours, stator and rotor models are detailed. The different flux densities are expressed as function of the vector $X$.

\section{Stator flux density}

The stator slotting effect is considered by means of an additional airgap length that can be calculated using the mean flux path under the slot opening [14]. Thus, idealized flux paths are shown in Fig. 8. The additional airgap length is given by (5).

$$
e_{s}(\nu)= \begin{cases}\frac{\pi}{\theta_{s l o t}} R_{e q} \nu\left(\theta_{\text {slot }}-\nu\right) & , \text { under the slot } \\ 0 & , \text { under a tooth }\end{cases}
$$

Where $\theta_{\text {slot }}$ is the slot opening angle, $R_{s i}$ is the internal radius of the stator and $\nu$ is the angle under the slot opening. The additional air-gap $e_{s}(\nu)$ is the equivalent length of the two 
parallel paths $\Gamma_{1}$ and $\Gamma_{2}$. The flux density of the stator teeth due to the airgap (Fig. 8) is determined by applying the flux conservation law to the tooth with a discretization of $1^{\circ} \mathrm{elec}$.

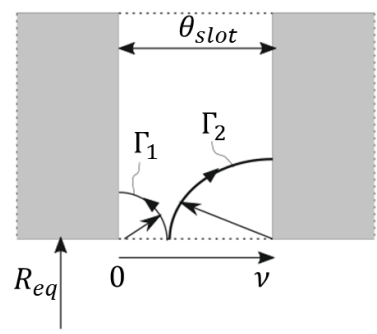

Fig. 8. Flux under slot opening

Under each tooth the flux density $\left(B_{s t_{a g_{0}}}\right)$ is given by (6). The flux linkage density from both sides of the slots around the tooth $B_{\text {stag-slot }}$ is given by (7)

$$
\begin{gathered}
B_{s t_{a g_{0}}}^{i}=\frac{R_{s i}}{w_{s t}} \int_{\theta_{i}-\theta_{s t} / 2}^{\theta_{i}+\theta_{s t} / 2} B_{a g}(\theta) d \theta \\
\forall i\{1,9\} ; \forall n \in\left\{\frac{\theta_{s t}}{2}, \frac{\theta_{s t}}{2}\right\} \\
B_{s t_{a g-s l o t} n}^{i}=\frac{R_{s i}}{w_{s t}}\left(\int_{\theta_{i}+n}^{\theta_{i}+(n+1)} B_{a g}(\theta) d \theta\right. \\
\left.+\int_{\theta_{i}-(n+1)}^{\theta_{i}-(n)} B_{a g}(\theta) d \theta\right)
\end{gathered}
$$

Where $\theta_{s t}$ is the tooth angular span and $\theta_{i}$ is the center angular position of the $i^{\text {th }}$ tooth. Additionally, the tangential leakage flux that links two adjacent teeth is considered. Detailed equations are referenced in [6]. The total flux density in the stator teeth is calculated as the sum of the total flux density for each tooth and the leakage flux.

\section{E. Rotor flux density}

Fig. 9 gives the model of one rotor pole with radial and axial magnets. We consider iron pieces between magnets as flux guides. Each rotor $(r t)$ pole is divided into two zones, the flux $\phi^{\{z, f g, p\}}$ is given as function of zone number $(z)$, flux guide number $(f g)$ and pole number $(p o l)$.

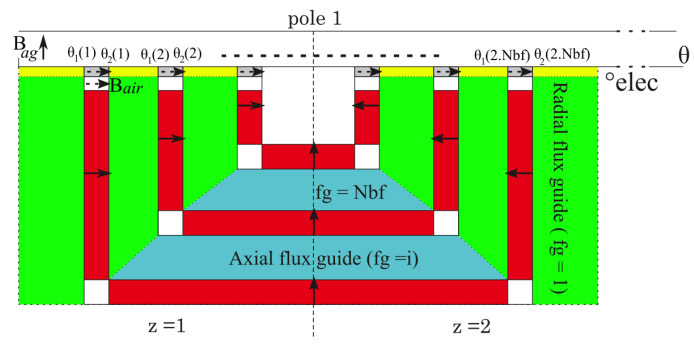

Fig. 9. Rotor pole general schematic

A linear interpolation is considered along each flux guide $(f g)$ mean path (Fig. 10). Thus, it is considered between $\phi_{f g_{\text {rad } 0}}$ and $\phi_{f g_{\text {radf }}}$ as well as between $\phi_{f g_{a x i 0}}$ and $\phi_{f g_{a x i f}}$. A linear variation between exterior iron bridges $(i b)$ is also considered along $x$ axis between $\phi_{i b_{f}}$ and $\phi_{i b_{0}}$. By applying the flux conservation law in each zone, a relation between the rotor flux and the global variables of the system can be established. An example is given in (8) and (9) for the flux guide between poles $(f g=1)$.

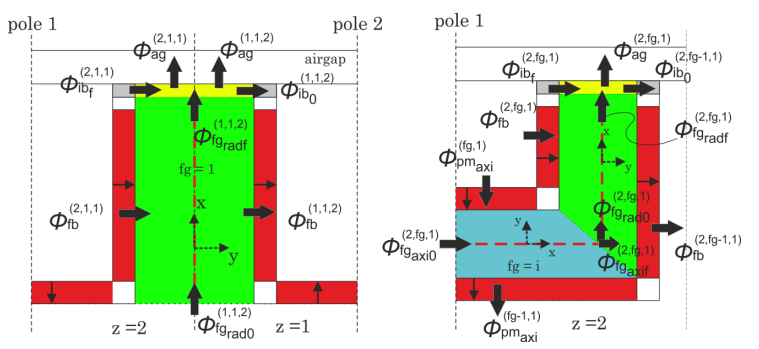

Fig. 10. left: mean flux path between two pole, right: mean flux path in a rotor flux guide

$$
\begin{array}{r}
\phi_{\text {rt } t_{\text {radf }}}^{(1,1, p o l)}=\phi_{\text {rt }}^{(2,1, p o l-1)}=\phi_{a g}^{(1,1, p o l)}+\phi_{a g}^{(2,1, p o l-1)} \\
+\phi_{i b_{0}}^{(1,1, p o l)}-\phi_{i b_{f}}^{(2,1, p o l-1)} \\
\phi_{r t_{\text {rad } 0}}^{(1,1, p o l)}=\phi_{\text {rt } t_{\text {rad } 0}^{(2,1, p o l-1)}=(-1)^{p o l} \phi_{f b}^{(1,1, p o l)}}^{(1,1, p o l)} \\
-(-1)^{p o l} \phi_{f b}^{(2,1, p o l-1)}+\phi_{\text {rt }}^{(1,1 a d f}
\end{array}
$$

Thus, for $f g \in\{2, N b f\}$, and $z \in\{1,2\}$, in radial direction the flux is given by :

$$
\begin{array}{r}
\phi_{f g_{\text {radf }}}^{(z, f g, p o l)}=\phi_{a g}^{(z, f g, p o l)}-(2-z) \phi_{i b_{f}}^{(z, f g-1, p o l)} \\
+(2-z) \phi_{i b_{0}}^{(z, f g, p o l)}+(z-1) \phi_{i b_{0}}^{(z, f g-1, p o l)} \\
-(z-1) \phi_{i b_{f}}^{(z, f g, p o l)}
\end{array}
$$

Where $N b f$ is the number of flux barriers $(f b)$. The flux conservation law was also applied for $\phi_{f g_{\text {rad }}}$ and for the axial direction $\phi_{f g_{a x i 0}}, \phi_{f g_{a x i 0}}$.

\section{F. Global system}

The global system is given by applying Ampere's theorem on the different contours (Fig. 7). For each angular position $\theta$, the contour $C_{1}$ equation is given by (11) and the contour $C_{2}$ by $12 . \theta$ varies between $0^{\circ}$ et $360^{\circ}$ elec.

$$
\begin{array}{r}
H_{a g}^{\theta} e_{t o t}^{\theta}-H_{a g}^{360} e_{t o t}^{360}+A t_{s}^{\theta}-A t_{s}^{360}+A t_{r}^{\theta}-A t_{r}^{360} \\
+m m f^{\theta}-m m f^{360}=0 \\
H_{a g}^{\theta} e_{t o t}^{\theta}-H_{a g}^{360} e_{t o t}^{360}+(-1)^{p o l}+A t_{s}^{\theta}-A t_{s}^{360} \\
+A t_{r}^{\theta}-A t_{r}^{360}+\sum_{m=1}^{n b-1}\left(H_{p m_{a x i}}^{(m, p o l)} e_{p m_{a x i}}^{(m)}\right) \\
+m m f^{\theta}-m m f^{360}=0
\end{array}
$$

Where $A t_{s}$ and $A t_{r}$ are the $m m f$ drop of the stator path (tooth + yoke) and the rotor path respectively. They are determined by means of stator and rotor flux density respectively. Similar model is applied on the two other contours $C_{3}$ and $C_{4}$. In addition, in order to complete the system, the flux conservation law is expressed in the airgap such that the mean value of $B_{a g}$ is equal to zero. The local saturation model of the iron ribs is detailed in previous work on radial flux machine [6]. The flux linkage in the different phases is calculated by means of the airgap flux density and leakage flux. The linkage flux in phase A is given by (13), 
where $N_{s}$ is the number of turns per coil, $m$ the number of coils per phase and $N_{c s}, N_{c p}$ are the numbers of circuits in series and in parallel

$$
\phi_{A}=\frac{N_{c s}}{N_{c p}} N_{s} \sum_{k=1}^{m} R_{s i} L \int_{\theta_{A-k}}^{\theta_{A+k}} B_{a g}(\theta) d \theta+\phi_{s t_{l f}}
$$

The average torque, the internal power factor and the internal voltage are calculated at 4 static positions for an accurate estimation [16]. They are defined in (14), (15) and (16) respectively.

$$
\begin{gathered}
T_{a v g}=\frac{3 p}{2}\left(\phi_{d} i_{q_{i n t}}-\phi_{q} i_{d_{i n t}}\right) \\
P F_{\text {int }}=\cos \left(\tan ^{-1}\left(\frac{-\phi_{d}}{\phi_{q}}\right)-\tan ^{-1}\left(\frac{i_{q_{i n t}}}{i_{d_{i n t}}}\right)\right) \\
V_{\text {int }}=\omega \sqrt{\phi_{d}^{2}+\phi_{q}^{2}}
\end{gathered}
$$

The comparison of these performances between the analytical model (AM) and the 2D-FEA is proposed in the next paragraph.

\section{G. Finite element validation}

The studied motor is $M_{1}$, the comparison of its performances is done on two different current levels: at $23 \mathrm{~A}$ (rms) which is the rated current and at $43 \mathrm{~A}$ (rms) which is the peak allowed current. Thus, two saturation levels are considered. The average mean torque error between FEA and analytical model (AM) is less than $2 \%$ (Fig. 11), the maximum torque value is given for current angle equal to $10^{\circ}$ elec, in 2D-FEA the torque value is $150 \mathrm{Nm}$ and $150.7 \mathrm{Nm}$ in AM. Same conclusions for the power factor (Fig. 11), the AM and 2DFEA show good concordance.
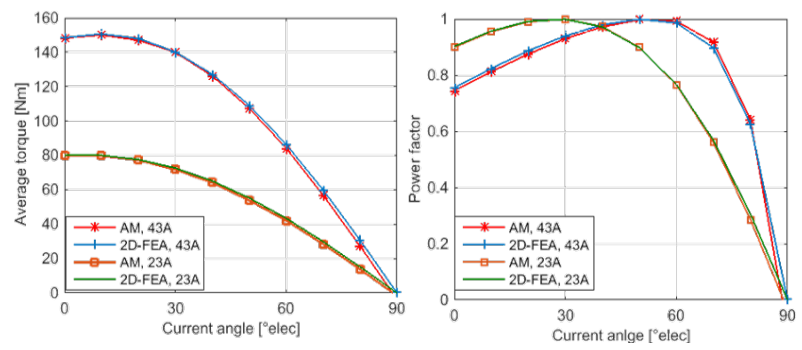

Fig. 11. Performance comparison between AM and 2D-FEA

\section{ELECTRICAL MODEL}

The internal voltage $\left(V_{\text {int }}\right)$ is delivered by the magnetic model. In order to calculate the power factor and the voltage at the motor terminals an electrical model is developed (Fig. 12). In this model, the phase resistance $R_{p h}$ is calculated as in [6], and the end-winding inductance per phase is determined by (17). The $\mathrm{d}-\mathrm{q}$ axis voltage at the motor terminals are obtained via the expressions in (18). $i_{d}, i_{q}$ are d-q axis current components.

$$
\begin{gathered}
L_{e w_{p h}}=\frac{\mu_{0} l_{e w} N_{s}^{2}}{2 \pi} \log \left(\frac{r}{R_{c}}\right) \frac{N_{b o b c} N c s}{N c p} \\
r=R_{c}+\frac{w_{c o i l}}{2} \text { and } \pi R_{c}^{2}=S_{c o i l} \\
v_{d}=-\omega \phi_{q}+R_{p h} i_{d}-L_{e w_{p h}} \omega i_{q} \\
v_{q}=+\omega \phi_{d}+R_{p h} i_{q}+L_{e w_{p h}} \omega i_{d}
\end{gathered}
$$

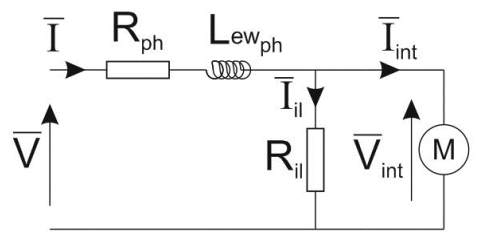

Fig. 12. Electrical circuit of the machine

\section{LOSS MODEL}

The loss model is also developed to determine the efficiency of the AF-SynPM. Thus, copper and iron losses are calculated to complete the analytical model. High resistivity ferrite magnets lead to negligible magnet losses. The stator iron loss components are calculated by applying the principle of superposition using (19) at the different harmonic frequencies [17]. The stator iron loss model was compared to a $2 \mathrm{D}$ finite element model using $\mathrm{JMAG}^{\circledR}$. The results for the motor $M_{1}$ at $43 \mathrm{~A}(\mathrm{rms})$ are given in Fig. 13, they show a good estimation of the stator teeth iron losses at different electrical angles.

$$
\begin{array}{r}
P_{\text {stator }}(B, f)=k_{H} f B^{\alpha_{i r}}+k_{E X C} f^{\frac{3}{2}} B^{\frac{3}{2}} \quad[W / k g] \\
+k_{E C} \sum_{k=1}^{\inf }(k f)^{\frac{3}{2}} B_{k}^{2} \frac{\sinh (\gamma \sqrt{k f})-\sin (\gamma \sqrt{k f})}{\cosh (\gamma \sqrt{k f})-\cos (\gamma \sqrt{k f})}
\end{array}
$$

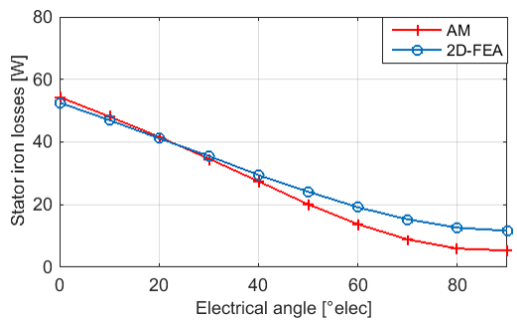

Fig. 13. Comparison of stator iron losses between AM and 2D-FEA

As for the rotor iron losses, they can reach significant values particularly the eddy current losses which are induced by the space harmonics components of the stator winding. We can express these iron losses by means of a simplified scaling method. For the radial flux machine, it is proportional to the stack length. As for the axial flux machine, an analysis of rotor iron losses with respect to the rotor height and the equivalent axial length $l_{e q}$ variation is proposed (Fig. 14). The iron losses vary linearly with respect to the equivalent
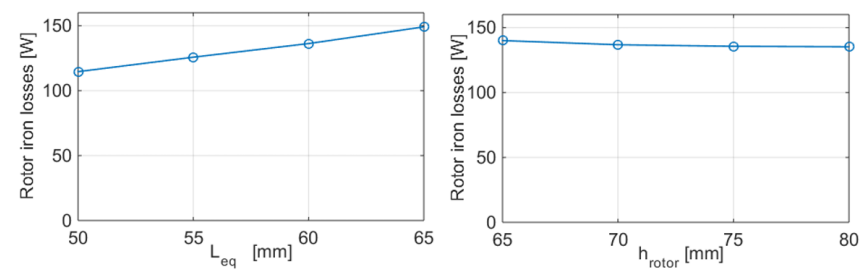

Fig. 14. Influence of machine length and rotor height on the iron losses

length and it is not influenced by the rotor height. The performances of the motor $M_{1}$ are close to the ones required; thus it is considered as a reference motor. An average value 
of iron losses $\left(P_{r e f}\right)$ with respect to its equivalent length $\left(l_{\text {ref }}\right)$ is considered. The iron losses $\left(P_{\text {rotor }}\right)$ for other similar structures are given by:

$$
P_{\text {rotor }}=\frac{P_{\text {ref }}}{l_{\text {ref }}} l_{s}
$$

The total iron losses $P_{i l}$ is the sum of $P_{\text {rotor }}$ and $P_{\text {stator. }}$ In the next section, the coupled electromagnetic model of the axial flux machine is optimized in order to meet the required specifications. It is compared to a radial flux machine.

\section{Multiobjectif Optimization with NSGA-II}

For the proposed application, our aim is to find the optimal characteristics of the axial flux machine that minimize the machine's cost $(c)$ and maximize its efficiency $(\mu)$. Thus, the design problem is turned into a bi-objective optimization problem under constraints: effects that are neglected when the $2 \mathrm{D}$ equivalent model is established. The performances of structure A" in 3D FEA model with reduced 3D leakage flux (3D FEA rl) is also presented in Table. V.

TABLE IV

OPTIMIZATION VARIABLES

\begin{tabular}{c||c|c}
$x$ & $\min$ & $\max$ \\
\hline Tooth angle: $\gamma_{s t}\left[{ }^{\circ}\right]$ & 8 & 12 \\
\hline Tooth height $: h_{\text {stator }}$ & 50 & 90 \\
\hline Nb. of turns: $N$ & 30 & 80 \\
\hline Barrier opening angle ratio $: \theta / \beta$ & 0.1 & 0.9 \\
\hline Barrier width: $w_{b}[\mathrm{~mm}]$ & 96.81 & 2.38 \\
\hline Current angle: $\alpha\left[{ }^{\circ} \mathrm{elec}\right]$ & 0 & 40 \\
\hline Current density: $J\left[\mathrm{~A} / \mathrm{mm}^{2}\right]$ & 3 & 10 \\
\hline Exterior radius: $R_{\text {ext }}\left[\mathrm{mm}^{2}\right]$ & 130 & 170 \\
\hline Interior radius: $R_{\text {int }}[\mathrm{mm}]$ & 80 & 140 \\
\hline Rotor height: $h_{\text {rotor }}[\mathrm{mm}]$ & 50 & 90 \\
\hline Radial PM height: $h_{\text {pm }}[\mathrm{mm}]$ & 40 & 80 \\
\hline
\end{tabular}

The errors between the new 3D model and the AM are $\int \underset{x}{\operatorname{minimize}} c(x)=$ cost $_{\text {copper }}+$ cost $_{\text {ironsheets }}+$ cost $_{\text {magnets }}$ radial flux machine (RFM) for the same application is pro$\left\{\underset{x}{\operatorname{maximize}} \mu(x)=\frac{T_{a v g} \Omega}{T_{a v g} \Omega+P_{C u}+P_{i l}}\right.$

subject to

$$
\begin{gathered}
\text { Torque }_{\text {avg }}>210 \mathrm{Nm} \quad, \quad \text { PowerFactor }>0.85 \\
\text { Voltage }<365 \mathrm{~V}, \quad \text { Current }<30 \mathrm{~A} \\
H_{p m}<H_{c J}=275 \mathrm{kA} / \mathrm{m}
\end{gathered}
$$

$\Omega$ is the rotational speed. The identified geometrical design variables are given in Fig. 15. The lower and upper limits of the design variables are given in in Table. IV. To solve this multi-objective constrained problem, the NSGA-II algorithm is used [12]. The same problem was solved in an earlier article [6] on a radial flux machine. Both optimization procedures were performed for a population of 400 individuals and 200 generations.

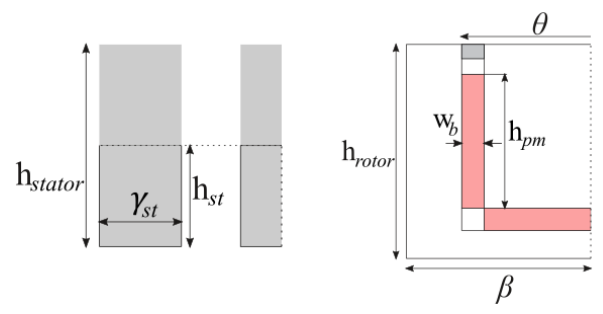

Fig. 15. Design variables of the stator and the rotor

\section{A. Optimization results and comparison}

The tradeoff between the two objectives for the axial flux machine (AFM) is presented by the Pareto front in Fig. 16. The two ends of the Pareto front are denoted as A" and B" presented in Fig. 17. The maximum efficiency is found for point B" $95.58 \%$, as for A" it is $92.54 \%$ but the cost of the machine is $40 \%$ cheaper than B". In Table. V, the performances of point A" are compared between the AM, 2D-FEA and 3D-FEA. The maximum error is found for the average torque value and it is less than $10 \%$. The $6.2 \%$ discrepancy between AM and 3D-FEA is due to 3D side posed.

Firstly, a comparison between the radial flux machine and existing conventionnel structures is proposed in Table. V. The electrical machines are given in Fig. 18, a spoke type ferrite permanent magnet structure with 48 slots and 8 poles and distributed winding and a surface permanent magnet with 27 slots and 24 poles with concentrated winding. Since the radial flux machine is prototyped [6], a comparison of the cost is added.

In Fig. 17 points $A^{\prime}$ and A" represent respectively the RFM and AFM, both structures are at iso-efficiency (92.54\%), but the AFM is cheaper whereas its normalized cost is $0.59 \mathrm{pu}$ and that of the RFM is $0.615 \mathrm{pu}$. When comparing both structures at iso-cost (points A' and C') the AFM develops better rated torque and power factor. A detailed comparison of the performances is given in Table. VI. The torque density is given in $\left[\mathrm{kNm} / \mathrm{m}^{3}\right]$ of the axial flux machine as well as the torque with respect to permanent magnet volume $\left(V_{P M}\right)$ is higher than that of the radial flux machine. At same total material cost, the proposed axial flux machine delivers higher efficiency and performances.

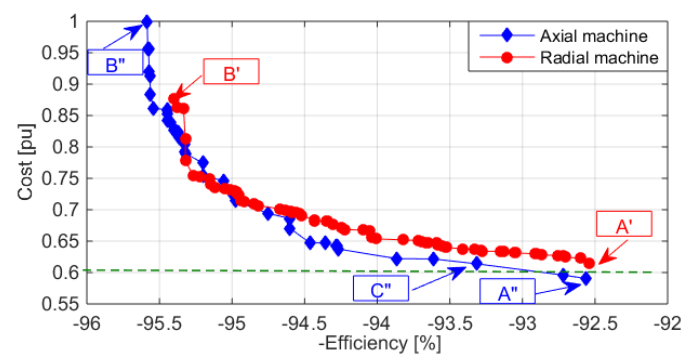

Fig. 16. Pareto fronts for radial and axial flux machines optimization

\section{CONCLUSION}

In this work, a novel axial flux synchro-reluctant permanent magnet assisted machine is proposed. Its performances are compared using SMC cores and steel sheets. A multiphysics analytical model is proposed. it was experimentally 


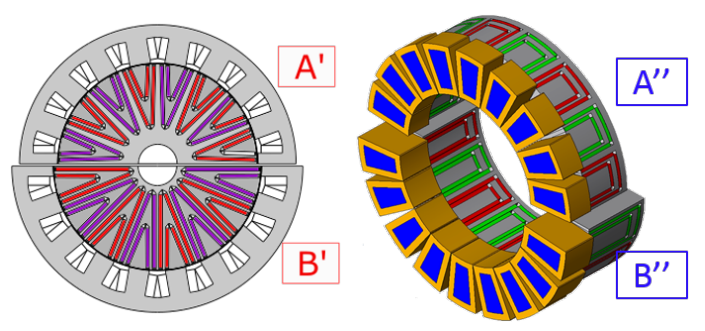

Fig. 17. Pareto ends of radial and axial flux electrical machines
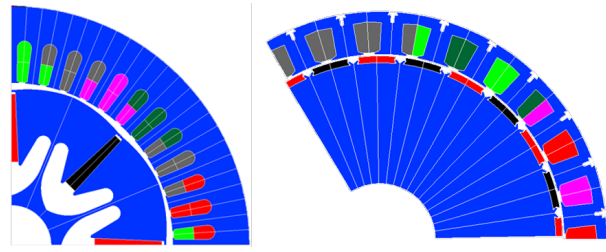

Fig. 18. Left: Spoke type machine, Right: Surface PM machine

TABLE V

COMPARISON OF 18/16 RADIAL WITH EXISTING INDUSTRIAL SOLUTIONS

\begin{tabular}{c|c|c|c|c} 
Model & $L[\mathrm{~mm}]$ & Torque $_{\text {avg }}[\mathrm{Nm}]$ & $\eta[\%]$ & cost $[p . u]$ \\
\hline $18 / 16$ & 200 & 210.6 & 92.17 & 1 \\
\hline $48 / 8$ & 200 & 210 & 86.7 & 1.24 \\
\hline $27 / 24$ & 190 & 211 & 92.18 & 1.3 \\
\hline
\end{tabular}

TABLE VI

COMPARISON OF A" PERFORMANCES

\begin{tabular}{c|c|c|c|c|c} 
A" Model & Torque $_{a v g}[N m]$ & $P F$ & $V[V]$ & $P_{i l}[W]$ & $\eta$ \\
\hline AM & 218 & 0.86 & 282 & 170.8 & 92.5 \\
\hline 2D FEA & 219.6 & 0.855 & 280.67 & 163.4 & 92.6 \\
\hline 3D FEA $_{r l}$ & 219.4 & 0.852 & 282.45 & 162.2 & 92.6 \\
\hline
\end{tabular}

TABLE VII

COMPARAISON OF RADIAL AND AXIAL FLUX

\begin{tabular}{c|c|c|c|c|c} 
Machine & Torque density & Torque $/ \mathrm{V}_{P M}$ & $P F$ & $V$ & $\eta$ \\
\hline A' (radial) & 16.7 & 95.72 & 0.85 & 337 & 92.5 \\
\hline C' (axial) & 25.05 & 108.15 & 0.893 & 287 & 93.3 \\
\hline
\end{tabular}

validated on a previously studied radial flux machine. A biobjective constrained optimization problem is formulated in order to maximize the efficiency and minimize the cost of the two machines. The problem is solved using NSGA-II algorithm. A comparison of the axial flux machine and a previous radial flux machine is conducted. It showed the capacity of the axial flux machine to develop a higher torque density. This first comparison is yet to be detailed to take into consideration the fabrication process of the axial flux structures and to include a thermal and a mechanical model.

\section{REFERENCES}

[1] J. Cros and P. Viarouge, Synthesis of high performance PM motors with concentrated windings, in Electric Machines and Drives, 1999. International Conference IEMD 99, 1999, pp. 725727.

[2] J. D. Widmer, R. Martin, et M. Kimiabeigi, Electric vehicle traction motors without rare earth magnets, Sustainable Materials and Technologies, vol. 3, p. 713, avr. 2015.

[3] D. Prieto, B. Daguse, P. Dessante, P. Vidal, and J. Vannier, Effect of magnets on average torque and power factor of Synchronous Reluctance Motors , XXth International Conference on Electrical Machines (ICEM), 2012, pp. 213219.

[4] A. Pina and L. Xu, Modeling of Synchronous Reluctance Motors Aidedby Permanent Magnets with Asymmetric RotorPoles , in IEEE International Electric Machines and Drives Conference (IEMDC), 2015, pp. 412418.
[5] N. Bianchi, E. Fornasiero, M. Ferrari, and M. Castiello, Experimental Comparison of PM-Assisted Synchronous Reluctance Motors , IEEE Transactions on Industry Applications, vol. 52, no. 1, pp. 163171, Jan. 2016.

[6] P. Akiki and al., Multi-Physics Design of a V-shape IPM Motor , in IEEE Transactions on Energy Conversion.

[7] A. A. Arkadan, T. M. Hijazi, et B. Masri, Design Evaluation of Conventional and Toothless Stator Wind Power Axial-Flux PM Generator, IEEE Transactions on Magnetics, vol. 53, no 6, p. 14, juin 2017.

[8] M. Sadeghierad, A. Darabi, H. Lesani, et H. Monsef, Rotor Yoke Thickness of Coreless High-Speed Axial-Flux Permanent Magnet Generator , IEEE Transactions on Magnetics, vol. 45, no 4, p. 20322037, avr. 2009.

[9] A. Parviainen, J. Pyrhnen, M. Niemel, Axial flux interior permanent magnet synchronous motor with sinusoidally shaped magnets, Proc. X Int. Symp. Electromagnetic Fields in Electrical Engineering, pp. 507512, 2001-Sept.

[10] C. H. T. Lee, K. T. Chau, C. Liu, T. W. Ching, et F. Li, A HighTorque Magnetless Axial-Flux Doubly Salient Machine for In-Wheel Direct Drive Applications , IEEE Transactions on Magnetics, vol. 50, no 11 , p. 15 , nov. 2014.

[11] T. Lambert, M. Biglarbegian, S. Mahmud, A novel approach to the design of axial-flux switched reluctance motors", Machines, vol. 3, pp. 27-54, 2015.

[12] K. Deb, A. Pratap, S. Agarwal, and T. Meyarivan, A fast and elitist multiobjective genetic algorithm: NSGA-II , IEEE Transactions on Evolutionary Computation, vol. 6, no. 2, pp. 182197, Apr. 2002

[13] M. Aydin, S. Huang, and T. A. Lipo, Axial flux permanent magnet disc machines: A review, EPE-PEMC 04, 2004.

[14] A. Fratta, G. P. Troglia, A. Vagati and F. Villata, Evaluation of torque ripple in high performance synchronous reluctance machines, in IEEE Industry Applications Conference Twenty-Eighth IAS Annual Meeting, Toronto, Ont., 1993, pp. 163-170 vol.1.

[15] N. Bianchi, M. Degano and E. Fornasiero, Sensitivity Analysis of Torque Ripple Reduction of Synchronous Reluctance and Interior PM Motors, in IEEE Transactions on Industry Applications, vol. 51, no. 1, pp. 187-195, Jan.-Feb. 2015.

[16] N. Bianchi and L. Alberti, MMF Harmonics Effect on the Embedded FE Analytical Computation of PM Motors , IEEE Transactions on Industry Applications, vol. 46, no. 2, pp. 812820, Mar. 2010.

[17] X. Jannot and al., Multiphysic Modeling of a High-Speed Interior Permanent-Magnet Synchronous Machine for a Multiobjective Optimal Design, in IEEE Transactions on Energy Conversion, vol. 26, no. 2, pp. 457-467, June 2011.

\section{BIOGRAPHIES}

Paul Akiki received his Engineering degree and Masters degree from Ecole Suprieure d'Electricit (Suplec), France, in 2014 and his PhD degree in electrical engineering from CentraleSuplec, Universit Paris-Saclay, France in 2017. His current research interests include design and optimization of electric machines and energy conversion systems.

Maya Hage-Hassan received her B.S. degree in mechanical engineering from the LU-Faculty of engineering, Lebanon, and a Ph.D. degree in electrical engineering from University Paris-Sud in 2014. She is now an Associate Professor at CentraleSuplec. Her current research interests include design of electric machines and drives.

Jean-Claude Vannier is a Professor and head of "Department of Energy and Power Systems" at CentraleSupelec, France. His primary research interest is in energy conversion systems and concerns the modeling, the design, and the optimization of these equipment for specific applications.

Mohamed Bensetti is a Professor at CentraleSupelec. His current research interests are Electromagnetic modeling, ElectroMagnetic Compatibility (EMC) and Power Electronics, including modelling, simulation and instrumentation.

Dany Prieto received the M.S. degree in Electrical Engineering from the University of Nantes, France, in 2011 and the Ph.D. degree from CentraleSupelec in 2015. Since 2015, he has been working with LeroySomer Motors as R\&D Electrical Engineer. His research interests include permanent magnet synchronous machines and induction motors with their power electronic supply.

Mike McClelland obtained his engineering degree from Leeds University in 1985 and $\mathrm{PhD}$ in 1994. He has been working for Emerson ever since on the electromagnetic, mechanical and thermal design of brushless machines and is now employed as Technical Director for Leroy Somer Motors \& Drives division. He is a Fellow of the Institute of Engineering and Technology (UK). 